\title{
Improving the care of COPD patients - suggested action points by the COPD exacerbations taskforce for reducing the burden of exacerbations of COPD
}

Chronic Obstructive Pulmonary Disease (COPD) is a preventable and treatable disease state characterised by airflow limitation that is not fully reversible. The airflow limitation is usually both progressive and associated with an abnormal inflammatory response of the lungs to noxious particles or gases [1].

Exacerbations are an important cause of morbidity and mortality in COPD and are a key driver of the medical, social and economic huirden associated with the disease [2]. The Gigrulicant impact of exacerbations on both patients and healthcare systems is vrell recognised Pollients with more frequent exacerb-iticiis have greater long-term decline in lung function, decreased quality of life, and lower survival rates [3-5]. Therefore, reducing exacerbations represents a key goal of treatment. Recent data show that approximately $50 \%$ of exacerbations may remain unreported and as a result, untreated [6]. In addition, treatment failures (particularly those resulting in hospitalisation) remain the single largest contributors to the total management cost [7]. Why should this be the case if a range of guidelines and options for prevention and treatment of exacerbations is available?

The current Global Initiative for Chronic Obstructive Lung Disease (GOLD), and the joint American Thoracic Society (ATS) and European Respiratory Society (ERS) COPD guidelines provide recommendations for the treatment of exacerbations $[1,8]$. Home management of COPD exacerbations involves increasing the dose and/or frequency of existing bronchodilator therapy. Systemic corticosteroids are also recommended in patients with more advanced COPD - classified as a forced expiratory volume in one second $\left(\mathrm{FEV}_{1}\right)$ of less than $50 \%$ predicted in whom they shorten recovery time $[9,10]$. Oxygen therapy is of central importance to the treatment of exacerbations in hospital Hospital management of exacerbations alsis induc'es the use of bronchodilaters and systemic corticosteroids. Nor-invacive ventilation is recommended in the reatment of exacerbations in patients with very severe cefo and hy're capneic respiratory failure [11]. An ibiotics are currently recommended for patients with COPD exacerbations with increased sputum purulence if they also have either increased dyspnoea or increased sputum volume [12].

A variety of pharmacological therapies have been demonstrated to be effective at preventing exacerbations. The long-acting anticholinergic tiotropium reduces exacerbations both compared with placebo by $14 \%$ and ipratropium by $24 \%$ $[13,14]$. Combining the long-acting inhaled $\beta_{2}$-agonist, salmeterol, and the short-acting anticholinergic, ipratropium, leads to fewer exacerbations than salmeterol alone $(10 \%$ fewer $)$ or placebo (23\%) [15]. The inhaled corticosteroid, fluticasone propionate, reduces the exacerbation rate per year by $25 \%$ compared with placebo in patients with more advanced COPD $\left(\mathrm{FEV}_{1}<50 \%\right)$ [16]. Combining long-acting inhaled $\beta_{2}$-agonists and inhaled corticosteroids also reduces exacerbations [17-19]. These effects are most evident in patients with $\mathrm{FEV}_{1}<50 \%$ in whom the salmeterol/fluticasone combination therapy reduced the rate of exacerbations by $30 \%$ compared with placebo [17]. A systematic review of oral mucolytic drugs 
showed that these drugs reduce the annual exacerbation rate by $29 \%$ compared with placebo [20]. Data from several large controlled studies have shown no benefit for the use of maintenance antibiotics in the prevention of exacerbations [21]. Non-pharmacological treatments such as pulmonary rehabilitation after an exacerbation have been shown to reduce the number of days in hospital over one year by 11 days compared with a control group [22].

Management of COPD is often multidisciplinary, with primary care playing the key role in identifying and treating the majority of exacerbations. Healthcare providers should aim to manage COPD patients in the community as much as possible by optimising early identification of COPD exacerbations and by initiating promptly appropriate treatment to reduce recovery time and the need for hospitalisation [23]. Home hospital programmes for patients with COPD exacerbations have been shown significantly to improve patient quality of life and to reduce healthcare costs by $38 \%$ compared with conventional treatment due to a reduced number of days in hospital [24]. Care plans need to recognise the multidisciplinary nature of COPD patient management, bearing in mind these patients' frequent co-morbidities (predominantly cardiovascular, metabolic and rheumatic), and should be integrated beturen prira care, secondary care and nurlinin proiessionals.

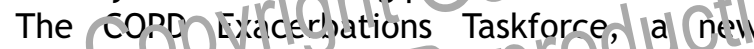
multidisciptinary group of interra: ond experts, was formed to develop a conjensus on how the prevention, treatment and management of exacerbations in patients with COPD could be improved. After reviewing available data on current treatment and management practice, the Taskforce reached a consensus with five key actions that urgently need to be implemented by healthcare professionals and providers to achieve more effective implementation of current evidencebased guidelines.

The Taskforce recognised that in order to improve the recognition and diagnosis of exacerbations, primary care professionals need to be able to identify undiagnosed COPD patients. To do this, development of a simple protocol or guidelines focusing on identifying exacerbations in the previously undiagnosed patient are essential. The guidelines should also encourage referral of patients with frequent exacerbations or an uncertain diagnosis to secondary care professionals.

The primary care team should be provided with clear guidance on how to recognise an exacerbation and should also be encouraged to use spirometry
Key Action Points of the Exacerbations Taskforce:

- Increase awareness that many COPD exacerbations can be prevented or treated

- improved education programmes for healthcare professionals, patients, caregivers and the general public.

- Increase patients' knowledge about their disease and provide clearer terminology to define and explain exacerbations

- improved programmes for patients and their caregivers

- improved communication between patients and their doctors

- Development of 'pathways' for the prevention and treatment of exacerbations

- the development of an exacerbation treatment algorithm and wider implementation of the Global Initiative for Chronic Obstructive Lung Disease (GOLD) guidelines

- Provide model programmes for multidisciplinary care

- formalising, sharing and promoting best practide prócocols in the prevention, tieatment and management of exare $D=$ tions

- Fincourage the use of spirometry in smokers and patients suspected of COPD - in particular, those with a history of frequent exacerbations

- greater education of healthcare professionals, healthcare providers and governments, on the importance of early, accurate diagnosis as a basis for appropriate treatment for COPD

routinely to confirm a COPD diagnosis in patients with chest symptoms. Improved education and awareness of the impact of exacerbations on quality of life and survival outcomes for COPD patients amongst secondary care professionals would help ensure appropriate treatment according to current guidelines and would prompt evaluation of efficacy to reduce the possibility of costly treatment failures.

Nurse roles vary considerably between healthcare systems; therefore, appropriate models of best practice in treating and managing exacerbations should be developed. Facilitation of nurse role models to train other nurses would support dissemination of best practice throughout 
the nursing profession and create key contacts for the provision of more information on clinical pathways or guidelines.

Improved patient knowledge of exacerbations and their impact was identified by the Taskforce as a key step in driving earlier diagnosis and treatment. Early recognition of exacerbation symptoms by the patient, and prompt treatment, is known to reduce both the time to recovery from an exacerbation and the need for hospitalisation [23]. Healthcare professionals have an important role in educating patients and empowering them to seek appropriate treatment and/or rehabilitation. Patients should also be educated on how to adapt their lifestyle and how to reduce environmental risk factors associated with exacerbations. Greater promotion of the rights of COPD patients to improved treatment and quality of life is also required to ensure that their needs are both understood and met. More research in this area is also needed.

The COPD Exacerbations Taskforce recommends urgent action based on its five key recommendations in order to ensure correct and early diagnosis and improved prevention, treatment, and management of COPD exacerbations. It is vital that multidisciplinary healthcare professionals, patients and healthcare payers are aware that exacerbations of COPD can be prevented and treated. Improvements in the multidisciplinary managemten ofexacerbations have the potential IS in pact positively on tat ent care, treatmicrit outcomes, ardotored nee directly healthcare utilisation costs.

\section{Acknowledgement}

The COPD Exacerbations Task Force is sponsored by an educational grant from GlaxoSmithKline (GSK).

\section{References}

[1] Global strategy for the diagnosis, management, and prevention of chronic obstructive pulmonary disease. Updated 2005. Accessed from www.goldcopd.com on 12 January 2006.

[2] Wouters EFM. The societal impact of COPD in North America and Europe: an economic analysis of the Confronting COPD survey. Respir Med 2003;97(Suppl C):S3-S14.

[3] Donaldson GC, Seemungal TA, Bhowmik A, Wedzicha JA. Relationship between exacerbation frequency and lung function decline in obstructive pulmonary disease. Thorax 2002; $57: 847-52$.

[4] Seemungal TAR, Donaldson GC, Paul EA, Bestall JC, Jeffries DJ, Wedzicha JA. Effect of exacerbation on quality of life in patients with chronic obstructive pulmonary disease. Am J Respir Crit Care Med 1998;157:1418-22.
[5] Connors Jr AF, Dawson NV, Thomas C, et al. Outcomes following acute exacerbations of severe chronic obstructive disease. Am J Respir Crit Care Med 1996;154:959-67.

[6] O'Reilly J, Williams AE, Rice L, Holt K. Incidence and impact of healthcare defined exacerbations amongst a cohort of primary care COPD patients [abstract]. ERS, September 2004.

[7] Miravitlles M, Murio C, Guerrero T, Gisbert R, for the DAFNE Study group. Pharmacoeconomic evaluation of acute exacerbations of chronic bronchitis and COPD. Chest 2002;121:1449-55.

[8] American Thoracic Society/ European Respiratory Society. Standards for the diagnosis and management of patients with COPD. 2004. Accessed from www-test.thoracic.org/copd on 12 January 2006.

[9] Davies L, Angus RM, Calverley PM. Oral corticosteroids in patients admitted to hospital with exacerbations of chronic obstructive pulmonary disease: a prospective randomised controlled trial. Lancet 1999;354:456-60.

[10] Thompson WH, Nielson CP, Carvalho P, Charan NB, Crowley JJ. Controlled trial of oral prednisone in outpatients with acute COPD exacerbation. Am J Respir Crit Care Med 1996;154:407-12.

[11] Clinical indications for noninvasive positive pressure ventilation in chronic respiratory failure due to restrictive lung disease, COPD, and nocturnal hypoventilation-a consensus conference report. Chest 1999;116:521-34.

[12] Stockley RA, O'Brien C, Pye A, Hill SL. Relationship of sputum color to nature and outpatient management of acute exacerbations of COP . Ches 20(0) 117:163845.

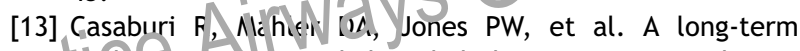
elatumon of once-daily inhaled tiotropium in chronic ubstructive pulmorar. disease. Eur Resp J 2002;19: $217-21$

[14] Vircken W, van Noord JA, Greefhorst AP, et al. Inproved health outcomes in patients with COPD during 1 yr's treatment with tiotropium. Eur Respir J 2002;19: 209-16.

[15] van Noord JA, de Munck DR, Bantje TA, Hop WC, Akveld ML, Bommer AM. Long-term treatment of chronic obstructive pulmonary disease with salmeterol and the additive effect of ipratropium. Eur Respir J 2000;15:878-85.

[16] Burge PS, Calverley PM, Jones PW, Spencer S, Anderson JA, Maslen TK. Randomised, double blind, placebo controlled study of fluticasone propionate in patients with moderate to severe chronic obstructive pulmonary disease: the ISOLDE trial. BMJ 2000;320:1297-303.

[17] Calverley P, Pauwels R, Vestbo J, et al. Combined salmeterol and fluticasone in the treatment of chronic obstructive pulmonary disease: a randomised controlled trial. Lancet 2003;361:449-56.

[18] Wouters EFM, Postma DS, Fokkens B, et al. Withdrawal of fluticasone propionate from combined salmeterol/fluticasone treatment in patients with COPD causes immediate and sustained disease deteriorations: a randomized controlled trial. Thorax 2005;60:480-7.

[19] Szafranski W, Cukier A, Ramirez A, Menga G, Samores R, Nahebdien S. Efficacy and safety of budesonide/formoterol in the management of chronic obstructive pulmonary disease. Eur Respir J 2003;21:74-81.

[20] Poole PJ, Black PN. Oral mucolytic drugs for exacerbations of chronic obstructive pulmonary disease: systematic review. BMJ 2001;322:1271-4.

[21] Francis RS, Spicer CC. Chemotherapy in chronic bronchitis. Influence of daily penicillin and tetracycline on exacerbations and their cost. BMJ 1960;5169:297-303. 
[22] Finnerty JP, Keeping I, Bullough I, Jones J. The effectiveness of outpatient pulmonary rehabilitation in chronic lung disease: a randomized controlled trial. Chest 2001;119:1705-10.

[23] Wilkinson TM, Donaldson GC, Hurst JR, Seemungal TA, Wedzicha JA. Early therapy improves outcomes of exacerbations of chronic obstructive pulmonary disease. Am J Respir Crit Care Med 2004;169:1298-303.

[24] Hernandez C, Casas A, Escarrabill J, et al. Home hospitalisation of exacerbated chronic obstructive pulmonary disease patients. Eur Respir J 2003;21:58-67.

Bartolome Celli*

Chief of Pulmonary and Critical Care, St Elizabeth's Medical Centre, 736 Cambridge Street, Brighton, MA 021354-2997, USA

Sue Cross Associate Director of Primary Care Nursing, Bedfordshire and Hertfordshire, UK

Ronald Grossman

Professor of Medicine, University of Toronto, Ontario, Canada
Peter Kardos Lung and Allergy Specialist, Maingau Hospital, Frankfurt, Germany

Svein Erik Myrseth

President, European Federation of Allergy and Airways Disease Patients Associations, Oslo, Norway

Roberto Rodriguez-Roisin Professor of Medicine, Hospital Clinic, Universitat de Barcelona, Spain

Jørgen Vestbo Professor of Respiratory Medicine, Wythenshawe Hospital, Manchester, UK

*Corresponding author. Tel.: +1 617789 2554; fax: +1 6175627756 .

E-mail address: bcelli@copdnet.org

(B. Celli)

11 October 2005

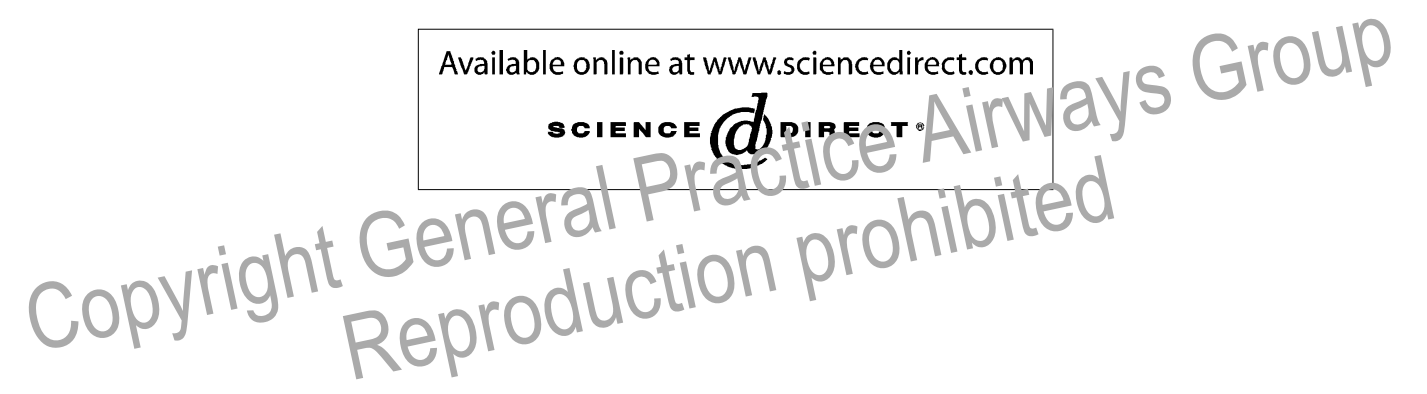

Available online at http://www.thepcrj.com 